\title{
The environmental impact of mining and its countermeasures
}

\author{
Jin $\mathrm{LI}^{1}$, Tong Tong ZHANG ${ }^{1}$, Wen YANG ${ }^{1}$, Yu ZHANG ${ }^{1}$ \\ China University Of Mining And Technology.BEI JING.China.100083
}

\begin{abstract}
Exploration of mineral resources had been part of the major means to promote economic development in China,but the devastating effect of mining on the environment is inevitable.Based on the analysis of factors of the environmental disasters caused by the mining methods,this paper systematically analyzes the influences of open pit mining on land resource,ecological system,geological and ecological environment,especially analyzes the effects on the environment and ecological system.Meanwhile,the paper points out that the mining scale,method and type are the main factors that affect the environment and ecology.At the end of this paper,some rational countermeasures, protection and control measures for environmental protection and governance are put forward on the basis of the research.
\end{abstract}

Key words: open-pit mining;environmental affect;inuence factors;countermeaflsures.

Mineral resources are an important material foundation of human survival and development, plays a role in the progress of the society.Till to 2010 , there are more than 74590 metal non-metal mines in China, including 8032 underground mines and 67862 open-pit,provides a strong guarantee of the national economic development ${ }^{[1]}$.Through China emphasized to avoid taking Western countries lay in the industrialization process of "pollution first, treatment later",but in fact we still on the same way,the environment is very grim. This paper focus on mining environmental problems, especially the open pit mining,such as the loss of resources,air pollution,damage of landscape and ecology.

\section{The environmental impact of mining}

\subsection{The environmental impact of open pit mining}

\subsection{1 the destruction of land resources}

The process of open-pit has a devastation impact on the land resources,such as overlying soil was dug and ground vegetation was destroyed.In China,most open-pit adopts external dump mode.The waste-dump soil covered $40 \sim 50 \%$ of total area of the open pit,at 1.5 2.5 times of mining land. Dump produced by each $1.0 \times 104 \mathrm{t}$ coal occupation $0.04 \mathrm{hm}^{2} \sim 0.33 \mathrm{hm}^{2}$ of the land,an average of $0.16 \mathrm{hm}^{2}$.And covered $16300 \mathrm{hm}^{2}$ areas of land in 2010, occupied a large number of land resources $^{[2]}$. Almost $1.4 \times 106 \sim 2.0 \times 106 \mathrm{Hm}^{2}$ areas of land were destructive and occupied by directly mining, and increased $2 \times 104 \mathrm{Hm}^{2}$ a year ${ }^{[3]}$. Waste rock piles 
and tailing piles also occupied a lot of land, according to the data show that produce $1 \mathrm{t}$ ore usually needs to strip 5 10t covered rock, while produce $1 \mathrm{t}$ copper can form on $400 \mathrm{t}$ waste rock and tailing ${ }^{[4]}$.Construction plant,equipment placement,construction traffic divided into ground fire and outcrop fire.Outcrop is on the brink of soil,high temperatures can make the soil dehydration,dense and hard, make mineral particles molten,changes its composition and structure.A distance of soil made ground fire has a lower surface temperature,and lower degree of burnt soil.Burnt soil is easy to break and serious decline in fertility.Can be seen in the serious damage to the land of open-pit.

\subsubsection{The destruction of the ecosystem}

During in the open pit process,stripping the topsoil and leaving the subsoil and slag,add the weight of machinery and equipment,so that the soil becomes hard,compacted,extreme lack of moisture and organic nutrient,substantial areas of forest and grassland destruction.Noise,vibration, water damage generated during mining inevitably leads to animal migration and death,the impact area is five to 10 times of the $\operatorname{men}^{[5]}$. Range of biological activities in the vicinity of the mining area are reduced.That decline the function and stability of the ecosystem. All over the world,there are 593 kinds of birds, 400 kinds of mammals, 209 species of amphibians and reptiles and more than $2 \times 104$ species of higher plants on the verge of extinction ${ }^{[6]}$. Usually,this kind destroy of biodiversity is irreversible. Although try to recovery and reclamation of vegetation in the damage zone, the effect is not very obvious. Mainly metal is quarter,granite, granulite and chlorite schist, that has strong wind resistance capabilities but weak in the natural ecological restoration ability ${ }^{[7]}$. Compared to the developed countries, the rehabilitation rate low $50 \%$,only $10 \%$ in China,the low rehabilitation rate expands the destruction region of vegetation ${ }^{[9]}$.Effect of coal fire on the ecological environment cannot be ignored. On the one hand,the ground temperature rises changed the physical and chemical properties of surface soil, reducing soil moisture and organic matter content, leading to soil depletion,plant growth difficult,reduce the biomass production; on the other hand, the surface temperature directly lead a large area of vegetation to die,more seriously to ignite forests,pastures,causing network also takes up lots of land.Besides that,coal fire damage on land resources is also quite serious.widespread damage to vegetation.

\subsubsection{Geological disasters}

Stability of open pit slope is one of the foremost environmental geological problems of open pit ${ }^{[4]}$. Artificially shaped slope scale has been expanded with the increase of mining deep,seriously damaged the natural balance to the stress and lead to artificial slope deformation, damage and slippage.One waterworks of Shougang Group operation,located in Qian'an,Hebei Province,occurred 109 times landslides and slope deformation instability since its operation.

In the mining process, will inevitably damage to vegetation,water,mountains,soil.All of this lead to water retention capacity decreased in surfaces, coupled with the concentrated interference and change from solid waste in the mining of the original mining area, and the solid waste piled messy,loose soil,causing serious soil erosion,leading to further deterioration of the surrounding environment,finally evolution to debris flow ditch,causing landslides.Development is harmful to the vegetation surrounding the mine, also lead the land productivity gradual decline,surface in the state of sand, gravel and barren ${ }^{[9]}$.Formed the desertification that gradually weakened from mining to outward.

Burning cavity,burnt rocks,combustion fracture and ground subsidence are the most obvious coalfield geological effect.Burning cavity is formed after the burning of shallow coal seam and the floating underground coal and coal pillar.It changes the balance of the seam roof and resulting in a large number of surface cracks and collapse pits.Grilled surrounding rock making the rocks,appeared to be different degrees of burns phenomenon, result the formation of burnt rocks.

\subsubsection{The impact on the human living environment}

\section{(1)Water Resource}

The waste-water pollution generated by open-pit 
water is very obvious.Large amounts, of acid,heavy metal ions,various kinds of mineral processing reagents,suspended solids washing waste-water and domestic sewage are produced in the mining process. Features of waste water emission are large quantity, complex composition,long duration and wide range. Secondly,toxic and harmful substances of solid waste through the long term of oxidation,erosion and leaching flows into underground.These waste-water through the way of runoff or infiltration to pollution the environment of mining and the surrounding area.Opencast mining also pumping and drain of groundwater,lower the groundwater level,less the amount of water, aquifer of Quaternary will be drained in the open-pit mining process, seriously influence the use of water resources.

\section{(2) Air Pollution}

The main air pollution generated by open-pit mining include:gas generated by large open-pit mining operation of machine equipment,power equipment, transportation equipment.Float coal mining steps,coal under side slopes, waste dump and miscellaneous coal scattered on the ground during transportation of miscellaneous coal,after prolonged exposure to air,the phenomenon of spontaneous combustion will produce large amounts of harmful gases, there is a lot of smoke associated. Motor transport in large opencast coal mine is very common,especially more than 100 tons of large vehicles are favored by the mine.it generates a large amount of exhaust.The harmful gases like $\mathrm{CH}_{4}$ and $\mathrm{CO}$, $\mathrm{CO}_{2}, \mathrm{NO}_{\mathrm{x}}, \mathrm{H}_{2} \mathrm{~S}$ etc.and other substances can lead to the destruction of the ozone layer,cause the greenhouse effect,but also the formation of acid rain,causeing secondary pollution,seriously affecting the production of human living environment.

Work of waste haulage along with a lot of dust generation and after the vehicle airborne dust effect is more obvious;Tailing surface like a desert,oxidation and wind erosion can make it become a source of periodicity dust storms,spring and winter is particularly serious.If the long-term without precipitation,settling dust blown by the wind and car driving again pollute the surrounding environment,a huge range of its spread.According to relevant information,dust can float to $10 \sim 12 \mathrm{~km}$ outside and dust capacity reached about $300 \mathrm{t} /\left(\mathrm{h} \cdot \mathrm{m}^{-2}\right)$, Grain yield decreased by $10 \%$ due to dust,and if people long-term inhalation of high concentrations of dust will affect their health and cause pneumoconiosis. ${ }^{[6]}$

(3) Noise pollution

The sound generated by transport vehicles and large machinery are the main source of noise mine open-pit mining.The noise level can reach $90 \mathrm{~dB}$ (A) above,sometimes as high as $120 \mathrm{~dB}(\mathrm{~A})$ This level often extends far beyond national standards. The noise environment not only can make listening mechanism of damaged,causeing insomnia, fatigue, dizziness, memory loss and other symptoms and affect sleep and rest,but also harm people's physical and mental health. ${ }^{[11]}$

(4) The burning loss of coal resources and the destruction of the environment

Opencast coal mining and mining which due to open pit mine periphery generated vertical cracks, result in oxygen along the slit channel with its underlying coal seams through oxidation and lead to coal combustion(Figure 1).Burning coal goaf and ground subsidence become a threat to the safety of the residents of the district fire trap.Yining and Kerr base coal fire occurred,people suddenly collapsed due to burn empty beast into the fire case. So it brings about a series of environmental and disaster problems such as resource loss,surface subsidence,air pollution and so on.

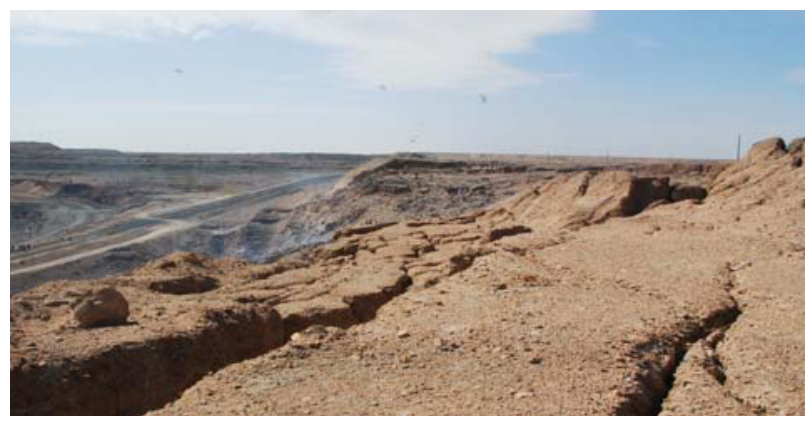

Figure 1 Xinjiang Hami basin three Ling open-pitmines and surrounding landscape after coal combustion

\subsection{THE ENVIRONMENTAL IMPACT OF UNDERGROUND MINING}

\subsection{1 the environmental impact of ground collapse}


After mining,the surrounding mechanical balance is destroyed,as the mined-out area increasing,the surface subsidence appeares becase the surrounding rock is not enough to resist the overlying rock mass gravity.After the surface subsidence, the ground structure, farmland and irrigation facilities will be damaged.In addition, Bridges,railways, and transmission lines will be affected in different degree.Deformation,rupture, displacement,and caving sink occour to roof strata which followed by surface subsidence due to the change of sinking.In 2011 , the total production of coal is 3.52 billion tons which $92 \%$ came from underground mining.According to incomplete statistics, one million hectares of land has been damaged due to the national underground coal mining subsidence by the end of 2011 which still increases at a speed of 70000 hectares a year.Among all the ecological environment problems caused by coal mining,the problems caused by the eastern plain area coal base should be paid more attention such as the damage of human settlement, the change of rural landscape and the large amount of village relocation.According to incomplete statistics, the number of removal will reach 2.7334 million in five lianghuai coal base and Great Plains in West Shandong base which outnumbered the total more than 1.3 million immigrants of the three gorges. For Jinzhong mining area, 509 villages and 97802 hectares of land suffered varying degrees of damage such disastrous consequences which attribute to ground subsidence.

\subsection{2 hydrogeological conditions}

Influence of underground mining on hydrogeological conditions include both surface water and groundwater.Ground subsidence caused by massively extracting of mineral resources ruins the water and water systems, resulting in the fall of groundwater and increase of surface runoff. New underground mined-out area makes the drainage characteristics of groundwater change.Effects on runoff regulation of groundwater system is corrupted. Dynamic rules of surface runoff in the basin is not only controlled by atmospheric precipitation and groundwater storage function,but also by the mine drainage and drainage of aquifer dynamic static
reserves.All the above factors makes the space-time distribution of water resources more unequal.(In addition, a large efflux of the mine wastewater not only seriously polluted surface water with in the basin, and possibly through osmosis contaminated groundwater,It is worrying.As for the influence on groundwater,To the exploitation, the inside of mine groundwater or threaten the safety of mine aquifer groundwater.must to be drainaged which changes the natural groundwater runoff and discharge conditions, thereby makes mine near of shallow layer groundwater was thinning dry. Near surface water turns to dry for drainage or artificial diversion.Huge waste of water resources lead to the decline of regional underground water level, deterioration of ecological environment,plant difficult growth,sand land of petrochemical.Coupled with the slow flow and invisibility of polluted groundwater, the contaminated area is difficult to determine.It is difficult to recover depending on natural purification of the aquifer itself alone. ${ }^{[15]}$

\section{Influencing factors of the environment in mine exploitation}

\subsection{Mining scale}

Mining scale and environmental damage have a certain relationship. ${ }^{[16]}$ Improving the mine production will require more machinery and equipment,buildings and open spaces which will also generate waste solid water and gas,occupying surface and underground space larger as well. This will cause the reduction of production life required,far exceeding the environmental limits of self-regulatory,and more serious environmental pollution.

\subsection{Mining methods}

Open-pit mining needs lower-cost,conducive to mining of lower grade ore bodies,so as to improve the utilization of resources.On the other hand,open-pit mining severely damaged the surface landscape, seizing and destroying large areas of land resources, striggering geological disasters,seriously affecting living and production environment.Underground mining has relatively little influence on the surface 
landscape and environment but can cause surface subsidence,affect hydrogeological conditions and induce earthquake.

\subsection{Mining types}

In the process of exploitation,different types of mineral resources have environmental impacts are not the same.Combustible organic minerals will result in solid waste,waste rock dumps, as well as the emission of toxic and harmful substances,causing global warming or acid rain.Heavy metal pollution from mining of metal ores does great harm to humans and the environment.Building materials mining destroy mountains,vegetation and other natural landscapes directly.

\section{4 others factors}

Environmental impacts of mining is related with its surroundings.Levels of impact on the human environment different from the mining location, topography, and climate.Environmental damage close to the number of people affected,for example,A city with annual mine output of 50000 tons will receive more complaints than a remote deserted island with an annual output of 5 million tons when it comes to the environmental problems caused by mining.Local terrain and climate characteristics have an enormous impact on the mining environment.In the flat area,the river flows slowly,with less sediment in the water away.In contrast, at the high altitude wide, noise and dust air can spread quite far away.Hills rolling meant country matters,geomorphological features is very important.Located high in the top of the device is very conspicuous,noisy and dusty air will spread widely, installation of equipment in the Valley can only be seen in height at close range limited to a few; The surrounding hills have formed an effective barrier,so that noise and dust can not escape.The river at high altitude carries a large amount of sediment due to high flow velocity, and is deposited in a relatively flat low-lying area. And the precipitation, air temperature, humidity, wind and other climatic factors will strongly affect the diffusion of mine pollution to the surrounding environment. Therefore, the climate affects the intensity of pollution. The atmosphere plays a dominant role in the emission of waste gas, dust, noise and air, and the precipitation has a very important influence on the diffusion of the waste liquid.

\section{Environmental protection measures and recommendations}

\subsection{Sound environmental laws, regulations}

Although the our country has formulated the "environmental protection law","mineral resources law",the geological disaster prevention and control law"and other,but our country haven't formed a complete legal system, lead to long-term since the management of mine environment in our country is relatively weak, do not have a strong sense of the protection of the ecological environment,government and enterprises pay attention to the economic benefits, ignoring environmental protection,go a at the expense of the environment at the expense of economic development.First,sound and perfect our country's relevant legal system, in reference to foreign advanced environmental protection legal system based on, combined with the actual situation of our country's environmental protection, to develop suitable for the situation of our country's environmental protection system,which is currently carried out in our environmental protection an important guarantee. Secondly,intensify the propaganda of environmental protection laws and appealed to the people involved in environmental protection and supervision, improve the legal consciousness in the process of the exploitation of mineral resources, the resources according to the economic development of basic rules and national standardized mining development, can not be blind to predatory development;again,increase of environ -mental pollution violations punishment, to prevent local protectionism, from two aspects of economic and policy punish illegal behavior.

\subsection{Reclamation and utilization of open-pit mining}

Mining should take the method for mining and reclamation of all hands at the same time,inner dump open-pit mining method, We should take reclamation as 
an important link in the process of mining and take dragline method,back haul,back track freight.

Communicates with underground pits, reservoirs and ponds can be built,covering an area large enough to build artificial lakes and a water recreation area.For water depths shallower places,we can grow aquatic crops such as Lotus root and wild rice stem,for relatively flat water pits, through experimental studies, after transformation to the soil, planting suitable vegetation, Gradually formed a growing development way of combining farming,so that maximum benefit from the economic and environmental benefits .

For the destruction of land resources, biological reclamation of approaches you can take.Use of microbial fertilizer technology,aging and improvement of barren land,restore soil fertility;worked out a method of adopting"the mud into the sand,the sand into the mud"method,adjusting the proportion of sand and mud soil,thereby improving the tilth.For the protection of the ecological system, through the establishment of parks and protected areas to reduce the exploitation of mineral resources to habitat destruction, the maximum amount of formulation of different types of mineral resources development projects caused by the biological abundance index,makes in the actual production process in time to pay attention to protecting the development zone surrounding the biological diversity.For the prevention and controlling of geological disasters, due to mining formed a variety of slopes, in addition to restoration, we should evaluate the degree of slope stability and its influence on the surrounding environment,according to different stone revetment slope or slope.In order to prevent soil erosion can obstruct the solid waste; the dangerous slope,depending on the slope length divided by intercepting ditch and drainage ditch,drainage works and increase of vegetation coverage.

Sewage and waste water resource is the realization of opencast mine area to maximize the use and utilization of water resources in the most effective way, can build a small sewage treatment system can not only of the mining area of the sewage of purification treatment,but also can deal with domestic waste water from surrounding residents.To strengthen the rational design and management of drainage and irrigation system,to prevent the waste of water resources in the process of the development of mineral resources.In order to reduce the air pollution,the construction site should as far as possible the use of clean energy or liquefied petroleum gas as fuel;secondly,can also in the transport vehicle tarpaulin covered,try to reduce the loading and unloading height and the fallout promptly removed to prevent the spread of these wastes caused due to the action of wind,watering facilities in the construction area,transport vehicles for timely cleaning, concrete mixing as set in the outlet and other measures.

\section{3 measures taken in underground mining}

Of underground excavation in rock roadway and generated a lot of waste,not to the ground directly in the underground processing,can reduce the ground gangue heap,the elimination of pollution,can save the gangue underground,well on transportation costs. Gangue well technology is through a variety of technical means,gangue rock roadway excavated, transported to underground waste disposal field broken, through a pipe and the wind transport to the work surface backfill mined out area,do gangue underground. The gangue filling to fill both to eliminate the pollution of coal gangue surface emission,but also to reduce the surface and strata movement and subsidence area is reduced.

Perfect the management system of mine environment monitoring.Help and guidance in the local environmental monitoring station,routine of mine groundwater standard higher data monitoring, the establishment of groundwater environment database, provide detailed and reliable basic data for the development of enterprises and scientific research. Environment related departments establish regional groundwater monitoring network and compensation mechanism,the mainland area water environment real-time monitoring,in accordance with the "who develops protection,who destroyed who is restored, who pollution who governance"principle, urge the Mining Corporation to fulfill the groundwater environmental protection and restoration of the obligation,funds through multiple channels to raise, gradually complete the pit was closed after the groundwater environmental restoration,the 
simultaneous development of the mining area of economic development and environmental protection.

\section{References}

[1] Wang Yan, Cheng Hao, Zhang Yu, Wang Pengfei. Environmental protection and restoration of mining environment protection and restoration measures [J] Henan building materials, 2013 (4): 93-95

[2] Dai Liping. The influence of mining on ecological environment and ecological restoration in the coal mine area: a case study of [J]., 2010 (18): 109-110

[3] Ma Jing. Development and utilization of mineral resources and environmental protection $[\mathrm{J}]$ resource development and market.2003 (3): 151-153

[4] Li Tiefeng, Pan Mao. Environmental geology [M] higher education publishing, 2008.7

[5] Yu Lin, Wang Xueli. Discussion on the ecological protection in the environmental impact assessment of mine development $[\mathrm{J}]$ Xinjiang environmental protection, 2003, 25 (4):48-50.

[6] Gao Yaling, Yang Wei, Wang Shuo. The environmental effect of iron ore mining [J] Liaoning chemical industry, 2009, 38 (1): 62-65

[7] Jiang Zhen, Yun cable. Anshan Iron ore waste rock field ecological environment governance plan and technical method [J]. Jiangxi Journal of Agricultural Sciences, 2008, 20 (4): 102-104

[8] Heming Kui, Ding Hua. Strengthen the development of mineral resources on environmental protection and management of Sichuan [J]. environment, 2003, 22 (3): 86-90.

[9] Lin Chen. Effect of mining on geological environment and Control Countermeasures of $[\mathrm{J}]$. technology and market, 2013, 8 (20): 180-181

[10] Tu Scott. Effect of coal mining on the environment and countermeasure research of $[\mathrm{J}]$. mining research and development 2003, 23 (4): 8-10

[11] Wang Wen, Xiang you, Wang Guojun. Journal of Liaoning Technical University, 2002, (4), [J]. Journal of,, (in Chinese).

[12] Wang erde. China's coal mining destroyed 1 million hectares of coal base in the number of immigrants over the three Gorges [EB/OL]. http://finance.sina.com.cn/china/20121205/02061389 6525.shtml.

[13] song Hongjuan. Jinzhong coal mining impact on water environment evaluation and control measures of groundwater [J], 2009, 31 (2)

[14] Wang Zhihui. Analysis on the influence of coal mining on the environment and Countermeasures $[\mathrm{J}]$. Jiangxi coal science and technology, 2012, 3:115-116 [15] Chen Xuejun, Bin Xiuling, the influence of mine development on environmental quality [J]. Journal of Guilin University of Technology, 1996, 1 (16): 83-86 